\title{
The meanings of positive polarity minimizers in Japanese: a unified approach*
}

\author{
Osamu Sawada \\ Kyoto University/JSPS
}

\begin{abstract}
In Japanese there are multiple lexical items for positive polarity minimizers (hereinafter, minimizer PPIs), each of which can differ in meaning/use. For example, while sukoshi 'lit. a bit/a little' can only express a quantitative (amount) meaning, chotto 'lit. a bit/a little' can express either a quantitative meaning or an 'expressive' meaning (i.e. attenuation in degree of the force of a speech act). The purpose of this paper is to investigate the semantics and pragmatics of the Japanese minimizer PPIs chotto and sukoshi and to consider (i) the parallelism/non-parallelism between truth conditional scalar meanings and non-truth-conditional conditional scalar meanings, and (ii) what mechanism can explain the cross-linguistic and language internal variation between minimizer PPIs. As for the semantics/pragmatics of minimizers, I will argue that although the meanings of the amount and expressive minimizers are logically and dimensionally different (non-parallelism), they can systematically be captured by positing a single lexical item (parallelism). As for the language internal and cross-linguistic variations, it will be shown that there is a point of variation with respect to whether a particular degree morpheme allows a dimensional shift (i.e. an extension from a semantic scale to a pragmatic scale). Based on the above proposals, this paper will also investigate the pragmatic motivation behind the use of minimizers in an evaluative context.
\end{abstract}

Keywords: minimizer PPIs, expressive and amount minimizers, cross-linguistic/language internal variation, conventional implicature, dimensional shift

* I am grateful to Karlos Arregi, Ryan Bochnak, Anastasia Giannakidou, Tommy Grano, Larry Horn, Arum Kang, Chris Kennedy, Yusuke Kubota, Ai Matsui, Yoko Mizuta, Koichiro Nakamoto, Chris Potts, Harumi Sawada, Jun Sawada, Yukinori Takubo, Hiroaki Tanaka, Sanae Tamura, Toet Rudy, Masahiro Yamada, Suwon Yoon, Masaya Yoshida, Keiko Yoshimura and the audience at SALT 20 for their valuable comments and discussions. Parts of this paper were presented at CLS 46, LSA 2010, the annual conference of the Pragmatics Society of Japan (2009), and the Wed3 meeting at Kyoto University. I would like to thank the audiences at these events for their valuable comments and discussions. This research is based upon work supported by the Japan Society for the Promotion of Science (Grant-in-Aid for JSPS Fellows, Grant No: 22-2632). 
Osamu Sawada

\section{Introduction}

Let us observe the following examples:

a. Kono sao-wa \{chotto/sukoshi\} magat-teiru.

This rod-TOP a bit bend-STATE

'This rod is a bit/little bent.'

b. Kono heya-no fusuma-wa itumo \{chotto/sukoshi\}

This room-GEN sliding door-TOP always a bit

ai-teiru.

open-STATE

'The sliding door of this room is always open a bit'

In (1), the minimizers chotto/sukoshi directly combine with an absolute gradable predicate (e.g. Kennedy 2007) that posits a minimum standard. Thus in (1a) the speaker is measuring the degree of 'bentness' or 'openness' of the subject referent, relative to a zero point. ${ }^{1}$

However, chotto, but not sukoshi, can also appear in an environment where there is no gradable predicate it can combine with:

$\{$ Chotto/*sukoshi\} hasami aru?

A bit scissors exist

(Question)

'lit. Chotto are there scissors?'

$\{$ Chotto/*sukoshi\} mata denwa-si-masu.

(Assertion)

A bit again phone-do-PRED.POL

'lit. Chotto I will call you again.'

Matsumoto $(1985,2001)$ observes that this type of chotto is a 'lexical hedge' like kinda or sort of (sorta) (Lakoff 1972) and claims that it is used to weaken the degree of illocutionary force. Here, chotto does not contribute to the truth conditional interpretation. I will call the minimizer in (1) an amount minimizer and the minimizers in (2) and (3) expressive minimizers. It is interesting that a degree morphology that is used to express a truth conditional scalar meaning can also be used to express a non-truth-conditional conditional scalar meaning as well.

The purpose of this paper is to investigate the semantics and pragmatics of the Japanese minimizer PPIs chotto and sukoshi and to consider (i) the parallelism/nonparallelism between truth-conditional scalar meanings and non-truth-conditional

1 Note that sukoshi and chotto in (1) are PPIs. If the sentences in (1) are negated, the resulting sentences become ungrammatical. However, if the particle mo is attached to sukoshilchotto (i.e. sukoshi-mo, chitto-mo), the resulting compound behaves as an NPI, and the negative versions of (1) become grammatical. See Sawada in press for a detailed discussion of the polarity sensitivity of minimizer PPIs in Japanese. 
The meanings of positive polarity minimizers in Japanese

scalar meanings, and (ii) the cross-linguistic and language internal variation of minimizer PPIs.

As for the (non-) parallelism, I will argue that although the meanings of the amount and expressive minimizers are logically and dimensionally different, they can systematically be captured by positing a single lexical item. As for the crosslinguistic and language internal variations, it will be shown that the fact that in Japanese a degree morphology can be used both for expressing an amount scalar meaning and for expressing an expressive meaning is not unique to Japanese but is cross-linguistically pervasive, based on Greek data. However, I will also show that some languages or particular items within them do not allow such a dual-use phenomenon. I will argue that there is variation with respect to whether a language (or a particular morpheme) allows a dimensional shift (i.e. a shift from a truth-conditional scalar meaning to a non-truth-conditional conditional scalar meaning.)

The theoretical implications of this paper are that there is a parallelism between the adjectival domain and the speech act domain in terms of scale structures and that there is an extension from a semantic scale to a pragmatic scale but not vice versa.

This paper proceeds as follows: In section 2 we will consider the differences between the amount use and the expressive use in terms of semantics/pragmatics interface. I will argue that the meaning of the expressive minimizer is a conventional implicature (CI). Section 3 provides a unified account of the meanings of the amount and expressive minimizers. Section 4 focuses on the ambiguity between the amount and expressive uses of minimizers. In section 5 we will discuss the cross-linguistic and language internal variation of minimizer PPIs. Section 6 considers the pragmatic motivation behind the use of minimizers in an evaluative context. Section 7 is the conclusion.

\section{The amount use vs. the expressive use of minimizers}

There are several empirical diagnostics to distinguish between the amount minimizers and the expressive minimizers. First, the particle dake can only focus on an amount minimizer (Matsumoto 1985):

(4) Kono doa-wa $\{$ chotto/sukoshi $\}$-dake ai-teiru.

This door-TOP a little-only open-STATE

'This door is open a bit/little.' (= this door is slightly open)

$*\{$ Chotto $\}$-dake hasami nai?

(Question)

A little-only scissors NEG. exist

'lit. Only chotto aren't there scissors?'

The second diagnostic for distinguishing between the amount minimizer and the expressive minimizer is the presence or absence of the Horn scale. According 
to Horn (1972), quantitative scales are defined by entailment (See also Horn 1989; Gazdar 1979; Levinson 2000):

(6) A set of linguistic alternatives $\left\langle x_{1}, x_{2}, \ldots x_{n}\right\rangle$ such that $S\left(x_{i}\right)$ unilaterally entails $S\left(x_{j}\right)$, where $S$ is an arbitrary simplex sentence frame, and $x_{i}>x_{j}$, and where $x_{1}, x_{2}, \ldots, x_{n}$ are equally lexicalized items, of the same word class, from the same register; and "about" the same semantic relations, or from the same semantic field.

As for the amount minimizers, we can posit the following Horn scale:

$<$ totemo, sukoshilchotto>

(the amount minimizers)

Totemo is stronger than sukoshi/chotto because S(totemo) unilaterally entails S(sukoshi/chotto):

a. Kono sao-wa totemo magat-teiru.

This rod-TOP very bend-PERF

'This rod is very bent.'

b. Kono sao-wa $\{$ sukosi/chotto $\}$ magat-teiru.

This rod-TOP a bit bend-PERF

'This rod is a bit bent.'

(8a) entails (8b). By contrast, in the case of expressive minimizers, there is no linguistic item that can serve as an alternative to the expressive chotto:

(9) $<? ?$, chotto $>$

(the expressive minimizers)

Thus, the following sentences with the intensifier totemo 'very' are odd:

$\{*$ Totemo/chotto $\}$ hasami aru?

(Question)

Very /a bit scissors exist

'lit. $\{$ Totemo/chotto $\}$ aren't there scissors?'

It is important to notice that the above two diagnostics are closely related to each other. The expressive chotto cannot combine with the focus particles because it is impossible to posit a set of degree adverbs that are alternatives to chotto (i.e. a Horn scale). The exclusive dake is a focus-sensitive particle in the sense that by focusing on an element, they invoke a set of alternatives (e.g. Rooth 1985).

I will argue that the meaning of amount minimizers contributes to 'what is said,' whereas the meaning of expressive minimizers is a conventional implicature (e.g. Grice 1975; Potts 2005, 2007). The intuition behind this analysis is that the 
The meanings of positive polarity minimizers in Japanese

expressive minimizers satisfy Potts's definition of CI:

(11) Potts's definition of CI

a. CIs are part of the conventional meaning of words.

b. CIs are commitments, and thus give rise to entailments.

c. These commitments are made by the speaker of the utterance.

d. CIs are logically and compositionally independent of what is 'said.'

One piece of evidence that shows that the expressive minimizers are not part of 'what is said' is that, unlike the amount minimizers, the expressive chotto can co-occur with at-issue intensifiers or emphatic NPI items (Israel 1996):

(12) The expressive chotto and the intensifiers

a. Chotto jikan-ga zenzen nai-desu.

Chotto time-NOM at all NEG-PRED.POL

'Chotto I don't have time at all.'

b. Chotto koko-wa kanari kiken-desu.

Chotto here-TOP quite dangerous-PRED.POL

'Chotto this book is very expensive.'

(13) The amount sukoshi and the intensifiers.

a. *Koko-wa sukoshi kanari kiken-da.

This place-TOP a bit quite dangerous-PRED

'This place is a bit quite dangerous.'

b. *Kono sao-wa sukoshi sootoo magat-teiru.

This rod-TOP a bit quite bend-PERF

'This rod is a bit quite bent.'

(13) but not (12), is ill-formed because minimizers conflict with intensifiers on the level of 'what is said.'

Note that the expressive chotto (i.e. the CI chotto) is not a presupposition trigger. A presupposition is a proposition whose truth is taken for granted as background information in the utterance of a sentence. For example, the sentence 'Taro failed again' presupposes that 'Taro failed at least one time before the time of utterance', and this presupposition is part of common ground among the participants in the conversation. However, the expressive chotto does not have such a background requirement.

Furthermore, unlike presuppositions, the meaning of the expressive chotto can 
scope out of the complement of attitude predicates:

(14) (Context: a secretary is telling a visitor about Prof. Yamada's schedule)

Yamada-sensei-wa konsyuu-wa chotto jikan-ga

Yamada-teacher-TOP this week-TOP CHOTTO time-NOM

nai-to omo-te-orare-masu.

NEG.EXIST-that think-TE-SUB.HON-PRED.POL

At-issue: Professor Yamada thinks that this week he does not have time.

CI: I am weakening the force of my assertion.

In (14) the expressive chotto is speaker-oriented. The natural situation for (14) is one where the speaker (i.e. the secretary) is using chotto in order to weaken the illocutionary force of his/her speech act.

\section{Analyses: Deriving two meanings based on one lexical item}

Despite the above differences, I argue that the amount and expressive minimizers have exactly the same 'scalar meaning.' That is, their meanings are derived from a single lexical item:

$\llbracket$ sukoshi $/$ chotto $\rrbracket=\lambda G_{\langle d,\langle X, t\rangle\rangle} \lambda X . \exists d[d>\approx S T A N D \wedge G(d)(X)]$

(where $X$ is either an individual of type $\langle e\rangle$ or a speech act of type $\langle a\rangle$, and sukoshi always specifies $X$ as an individual)

In prose, the denotation in (15) says that 'the degree of $X$ with respect to the scale associated with the gradable predicate $G$ is slightly greater than a standard.' The crucial point here is that the status of the meaning of (15) changes depending on the type of $X$. If $X$ is an individual, the output of (15) is an at-issue meaning. On the other hand, if $X$ is a speech act, the output of (15) is a CI.

\subsection{The meaning of the amount minimizers}

Let us first consider the meaning of the amount minimizer. In order to understand the meaning of an amount minimizer, it is important to take into consideration the difference between relative gradable adjectives and absolute gradable adjectives:

a. Kono roopu-wa $\{$ sukoshi/chotto $\}$ nagai.

This rope-TOP a bit long

'This rope is a bit long.' (Standard = a contextual standard)

b. Kono sao-wa $\{$ sukoshi/chotto $\}$ magat-teiru.

This rod-TOP a bit bend-PERF

'This rod is bent.' (Standard = a minimum standard) 
The meanings of positive polarity minimizers in Japanese

The adjective nagai 'long' is a relative gradable adjective that posits a contextually determined standard. Thus, sentence (16a) is interpreted as 'the length of this rope is slightly greater than a contextual standard.' On the other hand, the adjectival predicate magat-teiru is an absolute gradable adjective (lower-closed scale adjective) that posits a minimum endpoint. Thus, sentence (16b) is interpreted as 'the bentness of this rod is slightly greater than a minimum endpoint (i.e. zero point).' What is crucial here is that the value of the standard (STAND) is sensitive to the kinds of adjectives present.

As for the meaning of gradable adjectives, I assume that they represent relations between individuals and degrees (Seuren 1973; Cresswell 1976; von Stechow 1984; Klein 1991; Kennedy 2007). Thus we can represent the denotations of nagai 'long' and magat-teiru 'bent' as follows:
a. $\llbracket$ nagai $\rrbracket=\lambda d \lambda x$. $\operatorname{long}(x)=d$
b. $\llbracket$ magat-teiru $\rrbracket=\lambda d \lambda x$.bent $(x)=d$

(18) shows the truth condition of (16b):

$$
\begin{aligned}
& \llbracket \text { sukoshi/chotto } \rrbracket(\llbracket \text { magat }-t \text { eiru } \rrbracket)(\llbracket \text { konosao } \rrbracket) \\
& =\lambda G_{\langle d,\langle X, t\rangle\rangle} \lambda X . \exists d[d>\approx \operatorname{STAND} \wedge G(d)(X)] \\
& =\lambda X . \exists d\left[d>\approx \mathrm{STAND}_{\mathrm{ST}} \wedge \operatorname{bent}(X)=d\right] \\
& =\exists d\left[d>\approx \mathrm{STAND}_{\min } \wedge \operatorname{bent}(\text { this rod })=d\right]
\end{aligned}
$$

'The degree of bentness of this rod is slightly greater than a minimum standard.'

The following figure shows the logical structure of (16b) (The superscript a stands for an at-issue type):

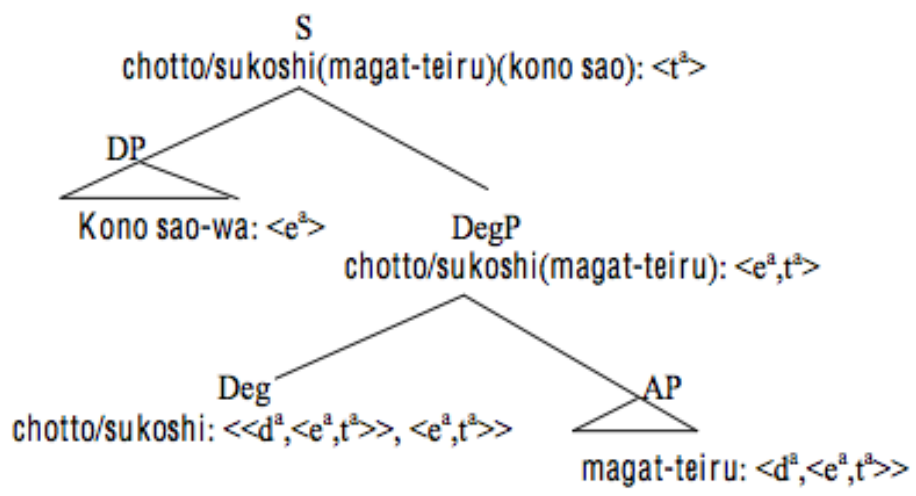


Note that if the gradable predicate is a relative gradable adjective like nagai 'long', then STAND in (15) is interpreted as a contextual standard. (See Kennedy 2007 for a detailed discussion of how the value of STAND is determined by the kinds of adjectives present.)

\subsection{The case of the expressive minimizer chotto}

We have so far considered the meaning of amount minimizers. Let us now consider the meaning of expressive minimizers based on the following example:

$$
\text { Chotto jikan-ga nai-desu. (Polite refusal) }
$$

a bit time-NOM NEG.EXIST-PRED.POLITE

'Chotto I don't have time.'

(I am refusing your request in a polite way.)

I argue that there is a parallelism between an amount meaning and an expressive meaning. That is, in the above examples the expressive minimizer combines with an invisible gradable predicate COMMITTED and the speaker is measuring the degree of commitment of a speech act (cf. Searle \& Vanderveken 1985 concept of the degree of illocutionary force).

As for the representation of clause type systems, I assume here, following Stenius (1967) and Krifka (2001), that an illocutionary operator combines with a sentence radical meaning (typically a proposition) to form a speech act (See also Tomioka 2010). This approach assumes a general type formation as follows:

(21) a. Basic types: $e$ entities, $t$ truth values, $p(=\langle s, t\rangle)$ propositions, $a$ speech acts.

b. A Speech Act operator is a function of the type of sentence radical it selects for type $a$.

c. The variables for type $a=\left\{U, U^{\prime}, U^{\prime \prime}, \ldots\right\}$

The logical structure of (20) is shown in (22) (The superscript a stands for an at-issue type and the superscript c stands for a CI type): 
The meanings of positive polarity minimizers in Japanese

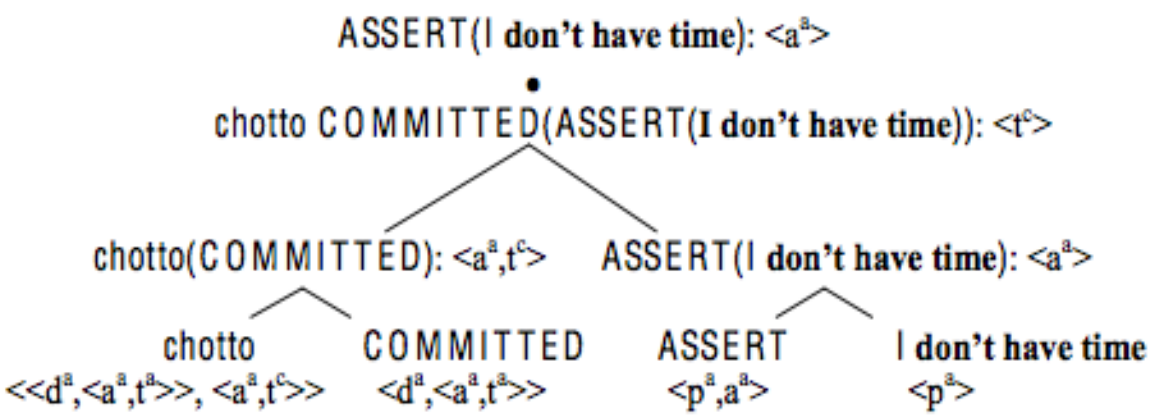

The expressive chotto takes the predicate COMMITTED and the speech act and returns a conventional implicature via the CI application (Potts 2005). (More specifically, the at-issue speech act is both passed on to the mother node and the argument to chotto(COMMITTED)). The advantage of this approach is that we can derive the meaning of the expressive chotto based on the same lexical item as the amount minimizers:

$$
\llbracket \text { sukoshi/chotto } \rrbracket=\lambda G_{\left\langle d^{a},\left\langle X, t^{a}\right\rangle\right\rangle} \lambda X . \exists d[d>\approx \mathrm{STAND} \wedge G(d)(X)]
$$

(where $X$ is either an individual of type $\left\langle e^{a}\right\rangle$ or a speech act force of type $\left\langle a^{a}\right\rangle$, and sukoshi always specifies $X$ as an individual)

In the case of the expressive minimizer, the variable $X$ corresponds to a speech act (rather than an individual). The crucial point here is that the type of output of (23) changes depending on the type of the variable $X$. If $X$ is an individual, the output is an at-issue scalar meaning, but if $X$ is a speech act, it is a CI scalar meaning.

As for the denotation of COMMITTED, we can represent it as follows:

$$
\llbracket \mathrm{COMMITTED} \rrbracket=\lambda d \lambda u \cdot \operatorname{COMMITTED}(u)=d
$$

Thus if the expressive chotto is combined with COMMITTED and the assertion that 'I don't have time', we get the following CI scalar meaning:

$$
\begin{aligned}
& \llbracket \text { chotto } \rrbracket(\llbracket \text { COMMITTED } \rrbracket)(\llbracket \text { ASSERT }(\text { I don't have time }) \rrbracket) \\
& =\lambda u_{\left\langle a^{a}\right\rangle} \exists d\left[d>\approx \operatorname{STAND}_{\min } \wedge \operatorname{COMMITTED}(u)=d\right] \\
& \left.=\exists d\left[d>\approx \mathrm{STAND}_{\min } \wedge \mathrm{COMMITTED}_{(\operatorname{ASSERT}}(\text { I don't have time })\right)=d\right]
\end{aligned}
$$

Note that I assume here that COMMITTED is a lower closed scale gradable predicate; thus, the standard is interpreted as a minimum standard.

This approach can capture the two different uses of chotto without positing different lexical items. The theoretical implication of this approach is that there is 
a parallelism between the adjectival domain and the speech act domain in terms of scale structures. Then what about a case like (26B)?:

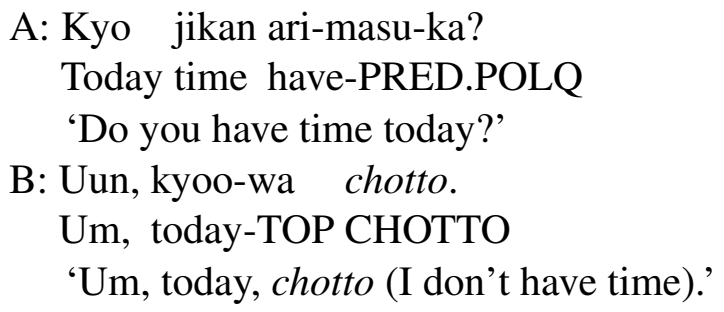

A: Kyo jikan ari-masu-ka?

Today time have-PRED.POLQ

'Do you have time today?'

B: Uun, kyoo-wa chotto.

Um, today-TOP CHOTTO

'Um, today, chotto (I don't have time).'

It seems to me that chotto in (26B) can be considered an 'implicit' expressive chotto that attaches to an invisible assertion (e.g. 'I don't have time' or 'I am busy', etc). Since the speaker utters uun, it is clear from the context that his/her response is going to be negative.

\section{Ambiguity between the amount minimizer and the expressive minimizer}

The expressive minimizer does not always have to be in a sentence initial position. There are cases where a sentence with a minimizer can be ambiguous between the amount reading and the expressive reading:

Kono hon-wa $\quad\{$ chotto/sukoshi $\}$ takai.

This book-TOP a bit expensive

'This book is a bit expensive.'

a. Amount reading: The degree of expensiveness of this book is slightly greater than a standard.

b. Expressive reading (with chotto): At-issue: this book is expensive. (CI: The degree of commitment of the assertion is slightly greater than a minimum.)

Since sukoshi can appear in (27), it is safe to consider that this sentence has an amount reading. Is there linguistic evidence that an expressive reading can arise even if a minimizer and a gradable predicate are adjacent to each other? My answer is yes. The following example with upper-closed scale adjectives clearly shows that an expressive minimizer can be situated immediately before an adjective:

(28) Sumimasen. Kono doa-wa ima \{chotto/??sukoshi\}

I am sorry This door-TOP now a bit

simat-tei-masu.

close-PERF-POLITE

a. ??The degree of closedness of this door is now slightly greater than a maximum degree.

b. This door is closed now. (CI: The degree of commitment of the assertion is slightly greater than a minimum standard.) 
The meanings of positive polarity minimizers in Japanese

Kare-no misu-wa $\{$ chotto/??sukoshi $\}$ akiraka-da. He-GEN mistake-TOP a bit certain-PRED

a. ??The degree of certainty is slightly greater than a maximum standard. b. His mistake is certain. (CI: the degree of commitment of the assertion is slightly greater than a minimum standard.)

(30) Kono gurasu-wa ima-wa \{chotto/??sukoshi\} ippai-desu. This glass-TOP now-TOP a bit full-PRED.POL

a. ??The degree of fullness of this glass is slightly greater than a maximum degree.

b. This glass is full. (CI: the degree of commitment of the assertion is slightly greater than a minimum standard.)

We cannot get an amount reading in the above examples because the adjectives are all upper-closed scale adjectives that posit a maximum standard. For example, there is no amount reading in (28) because it does not make sense to say that the degree of 'closedness' of a door is slightly greater than a maximum standard. Notice, however, that the sentences have an expressive reading. The natural context where we can get this reading is one where the speaker is weakening the degree of commitment of the assertion in order to avoid imposing his/her (factive) idea on the addressee. Thus, it is possible to argue that the expressive chotto can be 'in situ', and that there is no strict correlation between the positions of minimizers and their interpretations.

One way to analyze the meaning of 'in situ' expressive minimizers is to assume that there is a mismatch between their syntax and logical structure: 


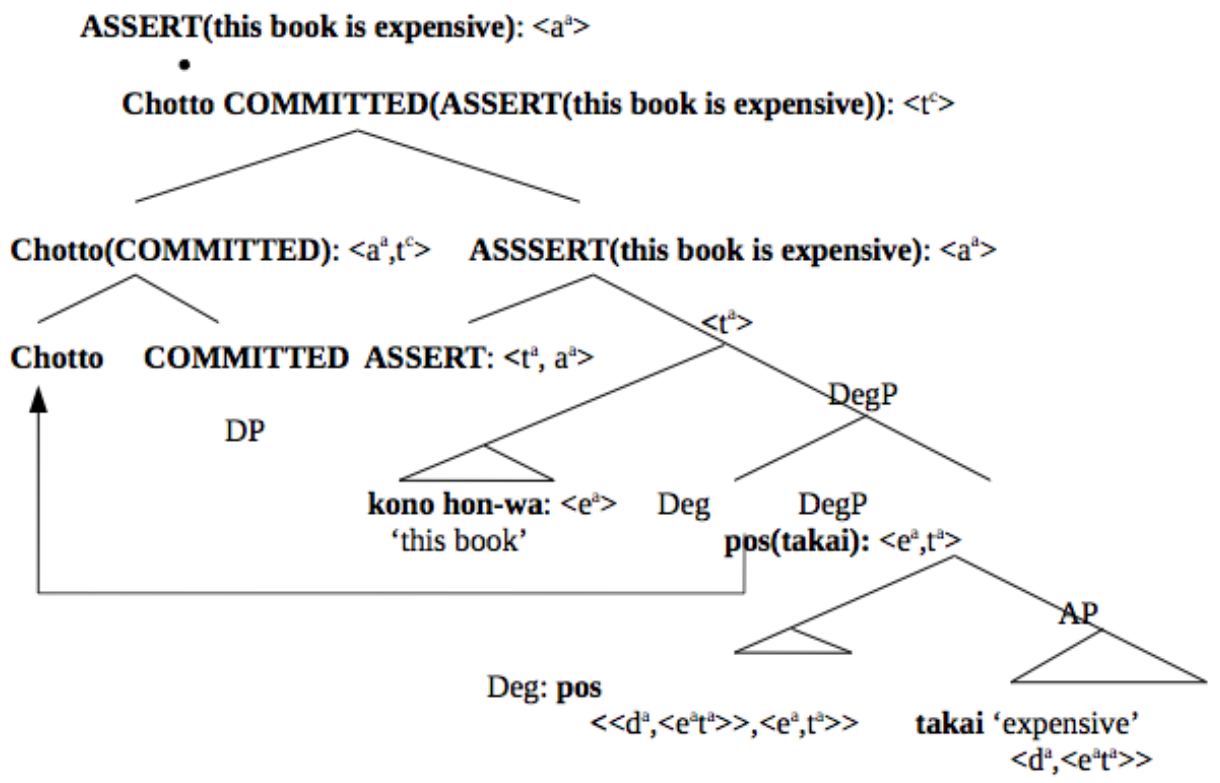

In syntax (surface form), the expressive minimizer is situated at the adjectival domain, but semantically it is interpreted at a speech act level. Note that in (31) there is an invisible degree morpheme pos, the function of which is to relate the degree argument of the adjectives to an appropriate standard of comparison (Cresswell 1976; von Stechow 1984; Kennedy \& McNally 2005, among others):

$$
\llbracket \operatorname{pos} \rrbracket=\lambda G \lambda x . \exists d[d \geq \operatorname{Stand} \wedge G(d)(x)]
$$

This analysis predicts that an overt degree morpheme can arise in the position of pos, a prediction that is borne out, as in the following example:

Koko-wa chotto kanari kiken-da.

Here-TOP a bit quite dangerous-PRED

'This place is chotto quite dangerous.'

Chotto in (33) is a CI scalar modifier, so there is no semantic conflict in using chotto and an intensifier in a single sentence (See also section 2). However, if we interpret chotto in (33) as an at-issue modifier, the sentence becomes odd.

\section{Cross-linguistic variations of CI minimizers}

Let us now consider the cross-linguistic and language internal variations of minimizer PPIs. We have so far argued that chotto can be used either as an amount minimizer 
The meanings of positive polarity minimizers in Japanese

or as an expressive minimizer. Interestingly, we can find a similar phenomenon in Greek: ${ }^{2}$

\section{Greek}

a. Ligi brizola parakalo? (Amount reading)

A bit.feminine steak please

'Please give me a bit of steak.'

b. Ligo brizola parakalo? (Expressive reading)

A bit.neuter steak please

'LIGO, please give me steak.' (Anastasia Giannakidou, personal communication)

Strictly speaking, ligi and ligo are lexically different (because of the difference in their modification structures), but they are clearly morphologically related and can be analyzed in the same way as the meanings of chotto.

What about languages like English? The English expressions a little/a bit are different from Japanese and Greek minimizers in that they cannot appear at a sentence initial position:
a. $*\{$ A little/a bit $\}$ are there scissors?
b. $*\{$ A littlela bit $\}$ I am going to go to shopping.

Does this mean that a little and a bit cannot behave as CI minimizers? I think this is a tricky question because in some cases, the English $a$ bit and a little seem to behave like CI minimizers:

This book is $\{$ a bit/a little $\}$ expensive.

One may think that a bit/a little in (36) is attenuating the degree of assertion that 'this book is expensive.' However, as the following examples show, unlike the case of chotto, a bit/a little cannot combine with upper-closed scale adjectives like closed and certain: ${ }^{3}$

a. ?? The door is a bit closed. (cf. 28)

b. ?? This is a bit certain. (cf. 29)

2 Thanks to Anastasia Giannakidou for providing the Greek data and helpful discussion. 3 Note that it is perfectly natural to use $a$ bit/a little with the upper-closed adjective full:

(i) This balcony is a bit full today.

This may be because full is a more flexible property in that we can always squeeze a few more people onto the balcony (whereas closed and certain are more rigid). Thanks to Ryan Bochnak, Tommy Grano and Chris Kennedy for their valuable discussions of this issue. 
If $a$ bit/a little can function as CI minimizers, we would predict that the above sentences would be natural, but in fact they are odd. Based on the above argument, I would like to consider that English $a$ bit/a little can only behave as at-issue minimizers.

\section{Pragmatic motivation behind the use of minimizers}

\subsection{Evaluativity constraint}

We have so far considered the meaning of the two types of minimizers and proposed a formal mechanism that can capture the similarities and differences between the two types of minimizer. This section considers the pragmatic motivation behind the use of minimizers in an evaluative context. It has been claimed that the use of the English minimizers a little and $a$ bit is restricted to specific contexts (Bolinger 1972; Ernst 1984; Leech 1983; Quirk, Greenbaum, Leech \& Svartvik 1985; Klein 1998).

For example, Bolinger (1972) claims that in a sentence with a little/a bit, there is an implication of 'more than expected', so that the use of these expressions is restricted to unfavorable (largely negative) conditional and desiderative contexts, as in the following examples:

(38) a. She's a bit fat to please anyone.

b. He was a bit inconsiderate (*considerate).

c. Let's be a little cautious this time.

(Bolinger 1972: 50)

Ernst (1984: 180) makes a similar observation. He observes that the adverbs $a$ bit and a little combine naturally with negatively tinged adjectives such as stupid, embarrassed, and envious.

$$
\text { Janet acted }\left\{\begin{array}{l}
\text { a bit } \\
\text { a little }
\end{array}\right\}\left\{\begin{array}{l}
\text { stupid }(\text { ly }) \\
\text { embarrassed } \\
\text { envious of her sister }
\end{array}\right\}
$$

Quirk et al. (1985: 447) claim that $a$ bit and a little can only occur in a predicative position, with adjectives with 'unfavorable' meanings, and with an implication of 'more than wanted':
a. The weather's a bit (too) hot.
b. *The weather's a bit lovely.
c. *a bit hot weather

(Quirk et al. 1985: 447)

What is interesting here is that the above tendency is cross-linguistically pervasive. Klein (1998) argues that Dutch has comparable general restrictions for een beetje 'a 
The meanings of positive polarity minimizers in Japanese

bit', wat 'somewhat' and enigszins 'somewhat.' For example, the following sentence with onattent is natural, but substituting attent would be unacceptable:

(41) Hij is een beetje onattent (*attent 'attentive')

$\mathrm{He}$ is a little inconsiderate. (Klein 1998: 78)

A similar observation can be made with regard to the Japanese minimizers chotto and sukoshi:

(42) Taro-wa $\{$ chotto/?sukoshi $\}$ kowai. (negative)

Taro-TOP a bit frightening

'Taro is a bit frightening.'

?? Taro-wa $\{$ chotto/sukoshi\} yasasii.

Taro-TOP a bit kind

'??Taro is a bit kind.'

(42) with sukoshi is not perfectly natural. This may be because sukoshi usually combines with 'objective' adjectives (i.e. measurable adjectives) rather than 'subjective' (i.e. emotional/non-measurable) adjectives (see Nishio 1972 for the distinction between objective and subjective adjectives). The adjective kowai is 'psychological', so it is difficult to posit an amount scale for it (i.e. a measurable scale). However, what is more crucial here is that there is a clear contrast between (42) and (44). We can summarize the above empirical facts as follows:

(44) The evaluativity constraint: Minimizer PPIs can naturally combine with negative evaluative adjectives, but they cannot combine with positive evaluative adjectives.

The question is where this constraint comes from. Semantically, there seem to be no reason why minimizers cannot co-occur with negative evaluative adjectives. Leech (1983) argues that the restriction comes from the following pragmatic principle:

(45) Pollyanna Principle: Participants in a conversation will prefer pleasant topics of conversation to unpleasant ones.

(Leech 1983: 147)

The Pollyanna Principle ensures that minimizers can occur only in a context where the speaker's utterance is construed negatively. According to Leech (1983: 148), 'the understatement disguises a bad report in a form which on the face of it permits a good interpretation. The unfavorable interpretation is arrived at indirectly, by implicature, and is thus weakened.' 
Osamu Sawada

\subsection{Rethinking the negative evaluative restriction}

Although the negative evaluative restriction seems to be intuitively right, there are many counter-examples in Japanese. Minimizers can combine with adjectives that have a positive/favorable meaning, as shown in (46) and (47):

Koko-no koohii-wa $\{$ chotto/?sukoshi $\}$ oisii-desu. Here-GEN coffee-TOP a bit tasty-PRED.POL

'The coffee in this place is a bit tasty.' (Please try it).

Kono hon-wa $\quad$ chotto/?sukoshi\} omoshiroi-desu.

This book-TOP a bit interesting-PRED.POL

'This book is a bit interesting.' (Please watch it.)

The adjectives in (46) and (47) are typical examples of predicates of personal taste (e.g. Lasersohn 2005). Although oishii 'tasty' and omoshiroi 'interesting' have a 'positive' evaluative meaning, they can co-occur with chotto. Here, the speaker uses chotto in order to avoid the imposition of his/her personal taste.

The above empirical facts suggest that the negative evaluative constraint is not based on the 'lexical meaning' of adjectives, nor is it governed by the preferencebased conversational principle (Pollyanna Principle). Instead, the use of minimizers is regulated by the speaker's pragmatic strategy of avoiding imposing his/her own ideas on the addressee (Matsumoto 2001; Akita 2005), or by the speaker's desire to avoid disagreeing with the listener in terms of 'personal taste' (Lasersohn 2005). In Japanese, the above pragmatic strategy is implemented by expressive minimizers rather than amount minimizers. In English, it may be implemented by at-issue minimizers.

\section{Conclusion}

In this paper we have investigated the semantics and pragmatics of the Japanese minimizer PPIs chotto and sukoshi and considered the parallelism/non-parallelism between truth conditional scalar meanings and non-truth-conditional conditional scalar meanings, as well as the cross-linguistic and language internal variation of minimizer PPIs. As for the (non-) parallelism, I argued that although the meanings of the amount and expressive minimizers are logically and dimensionally different, their meanings can systematically be captured by positing a single lexical item. As for the cross-linguistic and language internal variations, I argued that there is a point of variation with respect to whether a language (or a particular morpheme) allows a dimensional shift (i.e. a shift from a truth-conditional scalar meaning to a non-truth-conditional conditional scalar meaning.)

The theoretical implications of this paper are that there is a parallelism between 
The meanings of positive polarity minimizers in Japanese

the adjectival domain and the speech act domain in terms of scale structures, and that there is a natural extension from a semantic scale to a pragmatic scale, but not vice versa.

This paper leaves many things to be explored. First, a broader analysis needs to be conducted with respect to the complexity of scale structures in the CI dimension in general. In the at-issue domain, there are many degree adverbs that can combine with adjectives: totemo 'very', kanari 'quite', etc. However, in the $\mathrm{CI} /$ speech-act domain, it seems that there are not many degree morphemes. Why can't the intensifier totemo 'very' be used expressively in Japanese? Logically, it would seem to make perfect sense if there is an expressive totemo. ${ }^{4}$

Second, there is a question as to the varied nature of CI chotto. Interestingly, chotto can also be used as an attention-getter (Matsumoto 1985):

(A student is eating lunch at a library and a librarian says:)

Chotto chotto. Soko-no anata. Koko-de nani-o si-teiru-no?

Hey over there-GEN you. Here-LOC what-ACC do-ING-Q 'Hey, you. What are you doing here?'

There seems to be some connection between the expressive chotto and the attentiongetter chotto.

\section{References}

Akita, Emiko. 2005. Gendai nihongo no chotto ni tuite (Chotto in modern Japanese.). Soka Daigaku Bekka Kiyoo 17. 72-89.

Bolinger, Dwight. 1972. Degree words. Paris: Mouton.

Cresswell, Max J. 1976. The semantics of degree. In Barbara Partee (ed.), Montague grammar, 261-292. New York: Academic Press.

Ernst, Thomas B. 1984. Towards an integrated theory of adverb position in English. Bloomington: Indiana University dissertation.

Gazdar, Gerald. 1979. Pragmatics: Implicature, presupposition and logical form. London: Academic Press.

Grice, Paul. 1975. Logic and conversation. In Peter Cole \& Jerry Morgan (eds.), Syntax and semantics, III: Speech acts, 43-58. New York: Academic Press.

Horn, Laurence R. 1972. On the semantic properties of logical operators in English: UCLA dissertation.

4 English totally may be the opposite of expressive chotto:

(ii) You can totally wear the dress.

Thanks to Chris Potts for pointing out this example and providing valuable comments on this issue. See McCready \& Schwager 2009 for the meaning/use of the English word totally. 
Horn, Laurence R. 1989. A natural history of negation. Chicago: University of Chicago Press.

Israel, Michael. 1996. Polarity sensitivity as lexical semantics. Linguistics and Philosophy 19(6). 619-666. doi:10.1007/BF00632710.

Kennedy, Christopher. 2007. Vagueness and grammar: The semantics of relative and absolute gradable adjectives. Linguistics and Philosophy 30(1). 1-45. doi:10.1007/s10988-006-9008-0.

Kennedy, Christopher \& Louise McNally. 2005. Scale structure, degree modification, and the semantics of gradable predicates. Language 81(2). 345-381. doi:10.1353/lan.2005.0071.

Klein, Ewan. 1991. Comparatives. In Arnim von Stechow \& Dieter Wunderlich (eds.), Semantik: Ein internationales Handbuch der zeitgenössischen Forschung, 673-691. Berlin: Walter de Gruyter.

Klein, Henny. 1998. Adverbs of degree in Dutch and related languages. Amsterdam/Philadelphia: John Benjamins Publishing Company.

Krifka, Manfred. 2001. Quantifying into question acts. Natural Language Semantics 9(1). 1-40. doi:10.1023/A:1017903702063.

Lakoff, George. 1972. Hedges: A study in meaning criteria and the logic of fuzzy concepts. In $C L S$, vol. 8, 183-228.

Lasersohn, Peter. 2005. Context dependence, disagreement, and predicates of personal taste. Linguistics and Philosophy 28. 643-686. doi:10.1007/s10988005-0596-X.

Leech, Geoffrey N. 1983. Principles of pragmatics. London: Longman.

Levinson, C. Stephen. 2000. Presumptive meaning: The theory of generalized conversational implicature. Cambridge, MA: MIT Press.

Matsumoto, Yoshiko. 1985. A sort of speech act qualification in Japanese: chotto. Journal of Asian Culture IX. 143-159.

Matsumoto, Yoshiko. 2001. Tyotto: speech act qualification in Japanese revisited. Japanese Language and Literature 35(1). 1-16. doi:10.2307/489703.

McCready, Eric \& Magdalena Schwager. 2009. Intensifier. Paper presented at the workshop on the expressive and other kinds of non-truth conditional meaning (DGfS 2009).

Nishio, Toraya. 1972. Keiyooshi no imi yoohoo no kijututeki kenkyuu. (a descriptive study of the meaning and uses of Japanese adjectives.). Tokyo: Syuuei Syuppaan.

Potts, Christopher. 2005. The logic of conventional implicatures. Oxford: Oxford University Press.

Potts, Christopher. 2007. The expressive dimension. Theoretical Linguistics 33(2). 165-197. doi:10.1515/TL.2007.011.

Quirk, Randolph, Sidney Greenbaum, Geoffrey Leech \& Jan Svartvik. 1985. A comprehensive grammar of the English language. London: Longman. 
The meanings of positive polarity minimizers in Japanese

Rooth, Mats. 1985. Association with focus: University of Massachusetts at Amherst dissertation.

Sawada, Osamu. in press. Positive polarity minimizers: the semantics/ pragmatics interface. In Papers from the 46th Annual Meeting of the Chicago Linguistic Society, Chicago, IL: Chicago Linguistic Society.

Searle, John R. \& Daniel Vanderveken. 1985. Foundations of illocutionary logic. Cambridge, UK: Cambridge University Press.

Seuren, Piter A.M. 1973. The comparative. In Ferenc Kiefer \& Nicolas Ruwet (eds.), Generative grammar in Europe, 528-564. Dordrecht: Reidel.

von Stechow, Arnim. 1984. Comparing semantic theories of comparison. Journal of Semantics 3(1-2). 1-77. doi:10.1093/jos/3.1-2.1.

Stenius, Erik. 1967. Mood and language-game. Synthese 17(1). 254-274. doi:10.1007/BF00485030.

Tomioka, Satoshi. 2010. Contrastive topics operate on speech acts. In Caroline Féry \& Malte Zimmermann (eds.), Information structure: Theoretical, typological and experimental perspectives, 115-138. Oxford: Oxford University Press.

Osamu Sawada

Department of Linguistics, Kyoto University

Yoshida honmachi, Sakyo-ku

Kyoto, Japan, 606-8501

sawada.osamu@gmail.com 